\title{
Exenteração: estudo retrospectivo
}

\author{
Exenteration:a retrospective study
}

\author{
Milena Atique-Tacla ${ }^{1}$ \\ Luis Paves $^{2}$ \\ Max Domingues Pereira ${ }^{3}$ \\ PauloGois Manso ${ }^{4}$
}

\begin{tabular}{l} 
RESUMO \\
\hline Objetivo: Avaliar as características clínicas e epidemiológicas de pacientes \\
submetidos à exenteração da órbita. Métodos: Foram analisados retros- \\
pectivamente os prontuários de 21 pacientes submetidos à exenteração \\
entre agosto de 1998 e maio de 2003 . Foram avaliados dados referentes \\
a idade, sexo, raça, local de origem da lesão, acuidade visual pré- \\
operatória, tempo de evolução da doença, cirurgias prévias, complicações \\
pós-operatórias, diagnóstico histopatológico e uso de tratamento adju- \\
vante antes e/ou após a cirurgia. Resultados: A idade média dos pacientes \\
(12 homens e 9 mulheres) foi de 58,5 anos, sendo a maioria caucasianos. \\
Todos os pacientes apresentavam neoplasias malignas primárias, sendo \\
12 de origem palpebral, 6 conjuntivais e 3 orbitárias. O carcinoma \\
espinocelular foi a doença mais freqüente (52,4\%). Dos 21 pacientes, \\
$28,57 \%$ foram submetidos à cirurgia prévia relacionada à lesão que levou \\
à exenteração. Conclusão: A maioria dos pacientes analisados apresentava \\
tumores que geralmente se iniciam como lesões pequenas, mas que \\
podem se disseminar para a cavidade orbitária na ausência de tratamento \\
adequado.
\end{tabular}

Descritores: Exenteração orbitária; Enucleação ocular; Carcinoma de células escamosas; Neoplasias oculares; Invasividade neoplásica

\section{INTRODUÇÃO}

A exenteração orbitária é uma cirurgia radical realizada para casos de doenças neoplásicas, inflamatórias ou infecciosas avançadas, quando os procedimentos mais conservadores não são curativos. As principais indicações para realização de exenteração são as neoplasias malignas primárias de pálpebra e as de conjuntiva, com invasão orbital (principalmente o carcinoma basocelular e o espinocelular) ${ }^{(1-3)}$. Em geral, estas lesões são facilmente diagnosticadas e podem ser curadas se tratadas adequadamente no início da doença ${ }^{(4)}$. O objetivo deste estudo é avaliar as características clínicas e epidemiológicas de pacientes submetidos à exenteração orbital.

\section{MÉTODOS}

Foram analisados retrospectivamente os prontuários de 21 pacientes submetidos à exenteração orbital entre agosto de 1998 e maio de 2003, procedentes do setor de Órbita do Departamento de Oftalmologia - UNIFESP (16 pacientes) e do Setor de Tumores Cutâneos do Instituto Brasileiro de Controle do Câncer (IBCC) (5 pacientes).

Dados referentes a idade, sexo, raça, local de origem da lesão, acuidade visual no momento do diagnóstico, tempo de evolução da doença, cirurgias 
prévias, complicações pós-operatórias, diagnóstico histopatológico e uso de tratamento adjuvante antes e/ou após a cirurgia foram coletados.

A técnica operatória utilizada nestes pacientes foi exenteração total e enxerto de pele total removido da região inguinal ou clavicular. Os enxertos foram mantidos na cavidade orbital com gazes durante uma semana.

\section{RESULTADOS}

A idade dos pacientes variou entre 5 e 91 anos (média de 58,5 anos), sendo 12 homens e 9 mulheres. Dezessete pacientes eram brancos, 3 pardos e apenas 1 negro. Em todos os casos, as lesões que levaram à exenteração foram neoplasias malignas primárias. As lesões originaram-se nas pálpebras em 12 pacientes [ 5 casos na pálpebra inferior direita (PID), 3 casos no canto medial direito, 1 caso na pálpebra superior direita (PSD), 1 na pálpebra inferior esquerda (PIE), 1 na pálpebra superior esquerda (PSE) e 1 no canto medial esquerdo]. As lesões originaram-se na conjuntiva bulbar em 6 pacientes, sendo 2 casos na conjuntiva bulbar superior e 1 caso na conjuntiva bulbar inferior até fórnice do olho direito e 1 caso na conjuntiva bulbar superior, 1 na conjuntiva bulbar temporal e 1 caso na conjuntiva bulbar medial do olho esquerdo. A origem foi na órbita em 3 pacientes, sendo 1 na glândula lacrimal e 2 na região anterior da órbita.

Quanto à histologia, as lesões foram classificadas em car- cinoma espinocelular (CEC) em 11 pacientes, carcinoma basocelular (CBC) em 4 pacientes, carcinoma de glândulas sebáceas em 2 pacientes, rabdomiossarcoma em 2 pacientes, carcinoma mucoepidermóide de glândula lacrimal em 1 paciente e carcinoma anexial microcístico em 1 paciente. Os casos de carcinoma espinocelular tiveram origem nas pálpebras em 5 casos e na conjuntiva bulbar em 6 casos. Os casos de carcinoma basocelular originaram-se todos nas pálpebras. Os dois casos de carcinoma de glândulas sebáceas originaram-se respectivamente em canto medial esquerdo e em pálpebra inferior direita. Os dois casos de rabdomiossarcoma tiveram origem na órbita, o carcinoma mucoepidermóide originou-se em glândula lacrimal direita e o carcinoma anexial microcístico, em pálpebra superior direita.

A acuidade visual no momento de diagnóstico variou de 20/40 à ausência de percepção luminosa no olho acometido.

Seis pacientes $(28,57 \%)$ haviam sido submetidos a cirurgias prévias relacionada à lesão que causou a exenteração, realizadas em outros serviços. Em 3 destes pacientes, todos com diagnóstico de carcinoma espinocelular, foram realizadas duas cirurgias. Nos outros 3 pacientes, foram realizadas uma cirurgia prévia à exenteração, sendo que 1 paciente apresentou carcinoma basocelular e 2 apresentaram carcinoma espinocelular.

No período pós-operatório, 3 pacientes sofreram necrose parcial do enxerto, sendo que, em 2 a conduta foi expectante e em 1 foi realizado novo enxerto de pele sobre retalho de músculo temporal. Todos tiveram boa evolução com resultados satisfatórios até a última avaliação. Houve também um pacien-

\begin{tabular}{|c|c|c|c|c|c|c|c|}
\hline Paciente & Sexo & Idade & Raça & AV Pré & Cirurgias prévias & Origem da lesão & Anátomo-patológico \\
\hline 1 & $\mathrm{~F}$ & 66 & Pardo & SPL & não & PID & $\mathrm{CBC}$ \\
\hline 2 & $\mathrm{~F}$ & 78 & Branco & SPL & não & conj OD & CEC \\
\hline 3 & M & 43 & Pardo & PL & não & conj OE & CEC \\
\hline 4 & M & 78 & Branco & SPL & não & conj OD & CEC \\
\hline 5 & M & 42 & Branco & $20 / 100$ & não & cto med D & CEC \\
\hline 8 & M & 18 & Negro & $\mathrm{CD} 2 \mathrm{~m}$ & não & órbita D & rabdomios \\
\hline 9 & $\mathrm{~F}$ & 91 & Branco & SPL & não & PI D & CEC \\
\hline 10 & M & 59 & Branco & $20 / 400$ & não & conj OE & CEC \\
\hline 11 & M & 50 & Branco & PL & não & PI D & CA gl seb \\
\hline 12 & $\mathrm{~F}$ & 46 & Branco & CD $3 \mathrm{~m}$ & $\operatorname{sim}$ & conj OE & CEC \\
\hline 13 & M & 87 & Branco & CD $1 \mathrm{~m}$ & $\operatorname{sim}$ & PSE & CBC \\
\hline 18 & $M$ & 58 & Branco & MM & não & PID & $\mathrm{CBC}$ \\
\hline 19 & $\mathrm{~F}$ & 35 & Branco & SPL & $\operatorname{sim}$ & PIE & CEC \\
\hline 20 & $M$ & 69 & Branco & SPL & $\operatorname{sim}$ & PID & CEC \\
\hline 21 & $\mathrm{~F}$ & 40 & Pardo & $20 / 400$ & não & PS D & $\mathrm{CA}$ anex \\
\hline \multicolumn{8}{|c|}{ 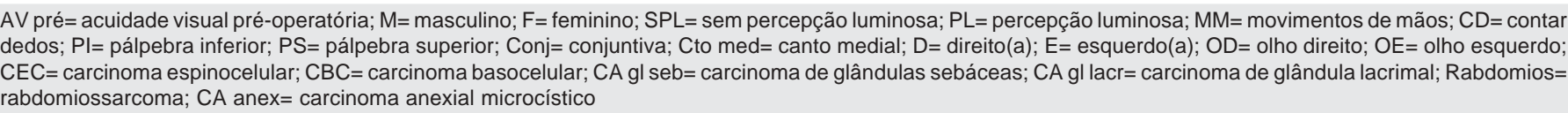 } \\
\hline
\end{tabular}


te que apresentou fístula para seio etmoidal e um paciente que apresentou diminuição de fórnice inferior após a exenteração. Nestes dois últimos, a conduta foi expectante e ambos tiveram boa resolução (tempo de seguimento médio de 29,5 meses).

A radioterapia foi usada como tratamento pós-operatório em seis pacientes, que apresentaram os seguintes diagnósticos: carcinoma de glândulas sebáceas moderadamente diferenciado ( 2 casos), carcinoma mucoepidermóide de glândula lacrimal (1 caso), carcinoma espinocelular bem diferenciado (2 casos) e rabdomiossarcoma (1 caso). Em todos os casos a radioterapia foi indicada pelo oncologista clínico em virtude da agressividade do comportamento biológico dos tumores observados nos pacientes em questão. A quimioterapia préoperatória foi administrada em ambos pacientes com diagnóstico de rabdomiossarcoma, também por indicação do oncologista clínico.

\section{DISCUSSÃO}

A exenteração da órbita é uma cirurgia extensa que envolve a remoção do globo ocular e dos tecidos moles contidos na cavidade orbital. Existem diversas técnicas descritas, porém apenas algumas delas são realizadas pelo oftalmologista. O princípio básico desta cirurgia é poupar a maior quantidade de tecido sadio possível. No entanto, algumas vezes é necessário um procedimento radical, com remoção inclusive de seios paranasais e estruturas intracranianas ${ }^{(5)}$.

Existem várias indicações para exenteração, dentre as

\begin{tabular}{|c|c|c|c|c|}
\hline Pacientes & $\begin{array}{l}\text { QT } \\
\text { (pré) }\end{array}$ & $\begin{array}{l}\text { Compli- } \\
\text { cações }\end{array}$ & $\begin{array}{c}R T \\
\text { (pós) }\end{array}$ & $\begin{array}{l}\text { Tempo de } \\
\text { seguimento }\end{array}$ \\
\hline 1 & não & não & não & $9 \mathrm{~m}$ \\
\hline 2 & não & não & não & $48 \mathrm{~m}$ \\
\hline 3 & não & não & não & $14 \mathrm{~m}$ \\
\hline 4 & não & não & não & $11 \mathrm{~m}$ \\
\hline 5 & não & $\operatorname{sim}$ & não & $30 \mathrm{~m}$ \\
\hline 6 & não & não & sim & $21 \mathrm{~m}$ \\
\hline 7 & não & não & $\operatorname{sim}$ & $29 \mathrm{~m}$ \\
\hline 8 & sim & sim & não & $33 \mathrm{~m}$ \\
\hline 9 & não & não & não & $43 \mathrm{~m}$ \\
\hline 10 & não & não & não & $45 \mathrm{~m}$ \\
\hline 11 & não & $\operatorname{sim}$ & $\operatorname{sim}$ & $51 \mathrm{~m}$ \\
\hline 12 & não & não & não & $27 \mathrm{~m}$ \\
\hline 13 & não & sim & não & $2 \mathrm{~m}$ \\
\hline 14 & não & $\operatorname{sim}$ & não & $11 \mathrm{~m}$ \\
\hline 15 & não & não & $\operatorname{sim}$ & $34 \mathrm{~m}$ \\
\hline 16 & $\operatorname{sim}$ & não & $\operatorname{sim}$ & $55 \mathrm{~m}$ \\
\hline 17 & não & não & não & $17 \mathrm{~m}$ \\
\hline 18 & não & não & não & $25 \mathrm{~m}$ \\
\hline 19 & não & não & $\operatorname{sim}$ & $19 \mathrm{~m}$ \\
\hline 20 & não & não & não & $51 \mathrm{~m}$ \\
\hline 21 & não & não & não & $45 \mathrm{~m}$ \\
\hline
\end{tabular}

quais podemos citar os tumores malignos de globo ocular e anexos (primários ou secundários), tumores malignos originários do crânio e seios paranasais estendendo-se para a órbita, trauma severo, deformidades congênitas do globo ocular e órbita, mucormicose e outras doenças fúngicas orbitais, casos severos de contraturas orbitárias ${ }^{(5)}$.

Em nosso estudo, todos pacientes submetidos à exenteração apresentavam neoplasia maligna e, em 12 pacientes $(57,14 \%)$, elas originaram-se na pálpebra. Estes dados estão de acordo com outras séries nas quais a exenteração foi mais freqüentemente realizada para tratamento de neoplasias malignas ${ }^{(2)}$ e a maioria destas lesões foram provenientes da pálpebra ${ }^{(1-2,6)}$.

A maioria de nossos pacientes são brancos, do sexo masculino e com idade acima de 60 anos, assim como os pacientes estudados em outros trabalhos publicados ${ }^{(1-2,6-8)}$.

$\mathrm{O}$ diagnóstico mais freqüente em nossos pacientes foi carcinoma espinocelular (CEC) seguido do carcinoma basocelular (CBC). Levin \& Dutton, em 1991, descreveram uma série de 99 pacientes submetidos à exenteração, mostrando também o CEC e o CBC como principais etiologias ${ }^{(2)}$. No entanto, outros trabalhos mostraram o carcinoma basocelular como a causa mais freqüente de exenteração orbital ${ }^{(1,3)}$ seguido do carcinoma espinocelular em um estudo ${ }^{(1)}$ ou do melanoma maligno e dos tumores de glândula lacrimal em outro ${ }^{(3)}$.

No período pós-operatório, três pacientes sofreram necrose de enxerto, um apresentou fístula de seio etmoidal para a órbita e outro apresentou diminuição de fórnice inferior. Não houve óbito relacionado à recidiva tumoral no período de seguimento do estudo (média de 29,5 meses). A radioterapia foi usada como tratamento pós-operatório em seis pacientes.

A maioria dos CEC orbitários são secundários, resultando de extensão direta de estruturas adjacentes, como seios paranasais e pálpebras. OCEC conjuntival é um tumor de baixo grau de malignidade, que raramente leva à metástase e que responde muito bem à excisão local ${ }^{(4)}$. A pele da região periocular também é um local comum para surgimento de carcinomas. Em nosso trabalho, apenas seis pacientes foram submetidos a tratamento prévio à exenteração, o que mostra uma ressecção inadequada da lesão ou falta de acesso do paciente aos serviços especializados. Em outros trabalhos analisados, vemos que a maioria dos pacientes exenterados já havia sido submetida a alguma cirurgia prévia com recidiva do quadro e progressão para invasão orbital, mostrando que, muitas vezes, o tratamento destas lesões não é simples e que estes pacientes necessitam de acompanhamento oftalmológico periódico ${ }^{(1,6)}$.

\section{CONCLUSÃO}

Concluímos que o grupo de pacientes analisado neste estudo apresenta características epidemiológicas semelhantes às descritas na literatura. A maioria deles apresentava tumores que geralmente se iniciam como lesões pequenas, mas que podem invadir a cavidade orbital na ausência de tratamento adequado. É importante fazer o diagnóstico preco- 
ce, o tratamento adequado destas lesões e o acompanhamento periódico cuidadoso a fim de detectar e tratar prontamente eventuais recidivas, evitando que os pacientes evoluam para cegueira, mutilação e até mesmo óbito.

\section{ABSTRACT}

Purpose: To review all cases of orbit exenteration performed at the Orbit Sector, Ophthalmology Department - Federal University of São Paulo, from 1998 to 2003. Methods: We reviewed conditions leading to orbital exenteration in 21 patients at the Orbit Sector of UNIFESP-EPM from August 1998 to May 2003. Data regarding sex, age, race, primary lesion site, visual acuity at the moment of diagnosis, previous surgeries related to the exenteration, type of performed surgery, histopathologic diagnosis, postoperative complications and use of adjuvant treatment were collected. Results: 21 patient charts were retrospectively analyzed. Ages ranged from 5 to 91 years (mean of 58.5 years). Of these, 12 were male and 9 were female, most of them Caucasian. All lesions that led to exenteration were malignant neoplasias; however, none were metastatic. Lesions originated from eyelids in twelve patients, from bulbar conjunctiva in six and from the orbit in three. Cases were also classified as squamous cell carcinoma (eleven cases), basal cell carcinoma (four cases), sebaceous gland carcinoma (two cases), rhabdomyosarcoma (two cases), mucoepidermoid carcinoma (one case) and adnexal microcistic carcinoma (one case). Visual acuity at the moment of diagnosis ranged from $20 / 40$ to no light perception. Only six patients had been submitted to previous surgeries related to the exenteration. After surgery, three patients suffered graft necrosis, one presented ethmoidal sinus fistula to the orbit and one presented orbital socket shrinkage. Six patients needed postoperative radiotherapy and two had been previously submitted to chemotherapy. Conclusion: Most patients analyzed in our study presented lesions that are usually small in the beginning; however, they can disseminate to the orbit in the absence of adequate treatment.

Keywords: Orbit evisceration; Eye enucleation; Carcinoma, squamous cell; Eye neoplasms; Neoplasm invasiveness

\section{REFERÊNCIAS}

1. Howard GR, Nerad JA, Carter KD, Whitaker DC. Clinical characteristics associated with orbital invasion of cutaneous basal cell and squamous cell tumors of the eyelid. Am J Ophthalmol. 1992;113(2):123-33.

2. Levin PS, Dutton JJ. A 20-year series of orbital exenteration. Am J Ophthalmol. 1991;112(5):496-501.

3. Rathbun JE, Beard C, Quickert MH. Evaluation of 48 cases of orbital exenteration. Am J Ophthalmol. 1971;72(1):191-9.

4. Johnson TE, Tabbara KF, Weatherhead RG, Kersten RC, Rice C, Nasr AM. Secondary squamous cell carcinoma of the orbit. Arch Ophthalmol. 1997;115 (1):75-8.

5. Small RG. Exenteration of the orbit: indications and techniques. In: Nesi FA, Lisman RD, Levine MR, Brazzo BG, Gladstone GJ. Smith's Ophthalmic plastic and reconstructive surgery. St Louis: Mosby-Year Book; 1998.

6. Leme VR, Oliveira MVD, Boeira Jr N, Cruz AAV. Causas de Exenteração. Arq Bras Oftalmol. 1999;62(1):75-7.

7. Tunc M, Char DH, Crawford B, Miller T. Intraepithelial and invasive squamous cell carcinoma of the conjunctiva: analysis of 60 cases. Br J Ophthalmol. 1999;83(1):98-103.

8. McKelvie PA, Daniell M, McNab A, Loughnan M, Santamaria JD. Squamous cell carcinoma of the conjunctiva: a series of 26 cases. Br J Ophthalmol. 2002; 86(2):168-73. Comment in: Br J Ophthalmol. 2002;86(12):1462. 